OPEN ACCESS

Edited by: Yanis Boumber,

Fox Chase Cancer Center, United States

Reviewed by:

Meng Xu Welliver,

The Ohio State University James Cancer Center, United States

Desiree Hao,

University of Calgary, Canada

*Correspondence:

Willem J. A. Witlox willem.witlox@mumc.n

Specialty section: This article was submitted to Thoracic Oncology, a section of the journal

Frontiers in Oncology

Received: 30 January 2018 Accepted: 18 June 2018

Published: 26 July 2018

Citation: Witlox WJA, Ramaekers BLT, Zindler JD, Eekers DBP, van Loon JGM, Hendriks LEL, Dingemans A-MC and De Ruysscher DKM (2018) The

Prevention of Brain Metastases in Non-Small Cell Lung Cancer by Prophylactic Cranial Irradiation.

Front. Oncol. 8:241 doi: 10.3389/fonc. 2018.00241

\section{The Prevention of Brain Metastases in Non-Small Cell Lung Cancer by Prophylactic Cranial Irradiation}

\author{
Willem J. A. Witlox ${ }^{1 *}$, Bram L. T. Ramaekers', Jaap D. Zindler' ${ }^{2}$, Daniëlle B. P. Eekers ${ }^{2}$, \\ Judith G. M. van Loon ${ }^{2}$, Lizza E. L. Hendriks ${ }^{3}$, Anne-Marie C. Dingemans ${ }^{3}$ \\ and Dirk K. M. De Ruysscher ${ }^{2,4}$
}

1 Department of Clinical Epidemiology and Medical Technology Assessment, Maastricht University Medical Centre, Maastricht, Netherlands, ${ }^{2}$ Department of Radiation Oncology (Maastro Clinic), Maastricht University Medical Centre, GROW School of Oncology and Developmental Biology, Maastricht, Netherlands, ${ }^{3}$ Department of Pulmonology, Maastricht University Medical Centre, GROW School of Oncology and Developmental Biology, Maastricht, Netherlands, ${ }^{4}$ Radiation Oncology, KU Leuven, Leuven, Belgium

Background: Non-small cell lung cancer (NSCLC) patients frequently develop brain metastases (BM), even though the initial imaging with brain CT or MRI was negative. Stage III patients have the highest risk to develop BM, with an incidence of approximately $30 \%$. BM can lead to neurocognitive disorders, loss of quality of life (QoL), and they are the most important factors influencing patient's overall survival (OS). Although a radical local treatment of BM may be possible with primary radiosurgery or after resection, the prognosis often remains poor. Preventing the development of BM through prophylactic cranial irradiation $(\mathrm{PCl})$ may improve the outcome of these patients.

Methods: Data from published randomized trials comparing $\mathrm{PCl}$ with non- $\mathrm{PCl}$ were sought using electronic database (PubMed) searching, hand searching, and by contacting experts. Trials were included if they considered a randomized comparison of $\mathrm{PCl}$ and non-PCl, enrolled NSCLC patients, excluded patients with recurrent or metastatic disease, and reported results on BM occurrence. Each randomized controlled trial (RCT) was assessed for methodological quality using the Cochrane collaboration's tool for the assessment of risk of bias. Study estimates were pooled using a fixed effects sample-weighted meta-analysis approach to calculate an overall estimate and 95\% confidence interval $(\mathrm{Cl})$. Results on PCl-related toxicity, QoL, and OS were only reported descriptively.

Results: Seven RCTs were included in the meta-analysis. In total, 1,462 patients were analyzed, including 717 patients who received $\mathrm{PCl}$ and 745 patients who did not. The risk of developing $\mathrm{BM}$ was significantly decreased through $\mathrm{PCl}$ (13\% reduction, $\mathrm{RR} 0.33$; 95\% Cl 0.22-0.45). PCl-related toxicity and QoL data were limited. Acute toxicity mostly included fatigue, skin-related toxicity, and nausea or vomiting. Late toxicities such as headache, dyspnea, lethargy, and low grade cognitive impairments were also reported in some of the included RCTs. Results on OS were inconclusive.

Conclusion: The risk of developing $\mathrm{BM}$ was reduced in patients who received $\mathrm{PCl}$ compared to patients who did not. To implement $\mathrm{PCl}$ as the standard treatment for patients 
with NSCLC, the impact of PCl-related toxicity on QoL should be further investigated, as well as long-term OS. A future individual patient data meta-analysis could produce definitive answers to this clinical question.

Keywords: non-small cell lung cancer, prophylactic cranial irradiation, brain metastases, toxicity, survival, quality of life

\section{INTRODUCTION}

Non-small cell lung cancer (NSCLC) is the most important cause of death due to cancer worldwide, and accounts for about $85 \%$ of all lung cancers. At present, more than $50 \%$ of all patients are diagnosed with adenocarcinoma, less than $10 \%$ are diagnosed with large cell cancer and the rest with squamous cell carcinoma. One-third of NSCLC present with locally advanced (stage III) disease, $20 \%$ with stage I-II, and the rest have metastases (stage IV) at diagnosis (1).

Non-small cell lung cancer patients frequently develop brain metastases (BM), even though the initial staging with brain CT or MRI was negative. The more advanced the disease stage is, the more frequent BM occur. They are also more frequent in adenocarcinoma than in squamous cell cancer (1). Stage III patients have a BM incidence of approximately 30\% (2). With longer overall survival (OS) and better imaging techniques, this percentage might increase. For example, in drive-mutated patients (e.g., EGFR and ALK) with a survival beyond 5 years, this percentage increases to more than $50 \%$ (3). BM can lead to neurocognitive disorders, loss of quality of life (QoL), and they are the most important factors influencing patients' OS (2). Although a radical local treatment of BM may be possible with radiosurgery or resection, the prognosis often remains poor. In order to improve QoL as well as OS, there is an unmet need to prevent the occurrence of BM (4).

Prophylactic cranial irradiation (PCI) was shown to significantly improve OS (5.4\% improvement of 3-year OS) in localized small cell lung cancer with complete remission or stable disease after multimodality treatment, as a result of decreasing BM incidence by about $50 \%$ (5). Also in patients with NSCLC, several randomized controlled trials (RCTs) studied the value of PCI in the prevention of BM (6-14). However, PCI might deteriorate QoL as a result of neurocognitive decline associated with cranial irradiation. Recently, a randomized phase III trial conducted by the NVALT/DLCRG (14) showed that PCI reduced the incidence of symptomatic BM [7.0\% in PCI vs $27.2 \%$ in no PCI, hazard ratio $0.25 ; 95 \%$ confidence interval (95\% CI) $0.11-0.58$ ]. Therefore, it is time to update the previously published literature and revisit the role of PCI in the prevention of BM in NSCLC patients. Here, we report on the results of a meta-analysis assessing the impact of PCI on the reduction of BM in primary stage I-III NSCLC patients, with PCI-related toxicity, QoL, and OS as secondary endpoints.

\section{METHODS}

\section{Data Collection}

Data from published RCTs comparing PCI with non-PCI were sought using electronic database searching between 1980 and December 1, 2017 (PubMed), hand searching (reference checking of individual studies and review articles), and by contacting experts in the field. The following keywords were used as search terms: "Carcinoma, Non-Small-Cell Lung," "NSCLC," "Cranial Irradiation," "Cranial Neoplasms/radiotherapy," "Brain Metastasis," "Overall Survival," and "RCT.” Details of the search strategy and corresponding flow chart can be found in Appendix S1 in Supplementary Material.

\section{Selection Criteria}

Trials were included if they considered a randomized comparison of PCI and non-PCI, enrolled NSCLC patients, excluded patients with recurrent or metastatic disease, and reported results on BM occurrence.

\section{Quality Assessment}

Two investigators (Willem J. A. Witlox and Bram L. T. Ramaekers) independently assessed each RCT for methodological quality using the Cochrane collaboration's tool for the assessment of risk of bias (15). This tool consists of seven items, including random sequence generation, allocation concealment, blinding of participants and personnel, blinding of outcome assessment, incomplete outcome data, selective reporting, and other sources of bias. Each item was scored "low risk," "unclear risk," or "high risk" of bias (Appendix S2 in Supplementary Material).

\section{Statistical Analysis}

Data of the primary endpoint (BM occurrence) was analyzed using Stata/SE 14.2 (16). Relative risk (RR) and accompanying 95\% CI of the individual studies were calculated based on the number of events and group totals. Subsequently, the estimates were pooled using a fixed effects sample-weighted meta-analysis approach to calculate an overall estimate and 95\% CI. Heterogeneity of the studies was tested using chi-square- and $I^{2}$-tests (15). Publication bias and small study effects were assessed by visual inspection of funnel plots and performing Egger's test, respectively $(17,18)$. If Egger's test is significant, a sensitivity analysis will be performed excluding small studies (weight $<10 \%$ ).

Results on PCI-related toxicity, QoL, and OS will only be reported descriptively.

\section{RESULTS}

\section{Literature Search and Quality Assessment of Publications}

The electronic literature search yielded 360 unique publications. Another two publications were identified through hand searching and contacting experts. After screening of titles and/or abstracts, 354 trials were excluded. One RCT (12) was excluded after reading the full text, because local treatment was different 
between both arms. Methodological quality of the remaining seven RCTs was checked and most of the items were at "low risk" of bias (Figure 1). Three studies (6-8) did only perform a brain scan when indicated by a change in neurological status of the patients, without adequately defining how neurological status was assessed. Therefore, the reviewers judged these studies to be at high risk of introducing bias in assessing the outcome. The reviewers suspected possible selection bias in the study of Cox et al. (6), because randomized patients were excluded from evaluation, which is not in accordance with the intention to treat principle. Although blinding of participants and personnel was not performed in any of the included studies, based on the nature of the intervention, this item was judged by the reviewers as low risk of introducing bias (Appendix S2 in Supplementary Material).

\section{Characteristics of the Included Trials}

Characteristics of the seven included trials are listed in Table 1 below. There were little differences between the selected patient groups of the trials. Four studies $(9,10,13,14)$ included stage III

\section{Risk of bias assessment}

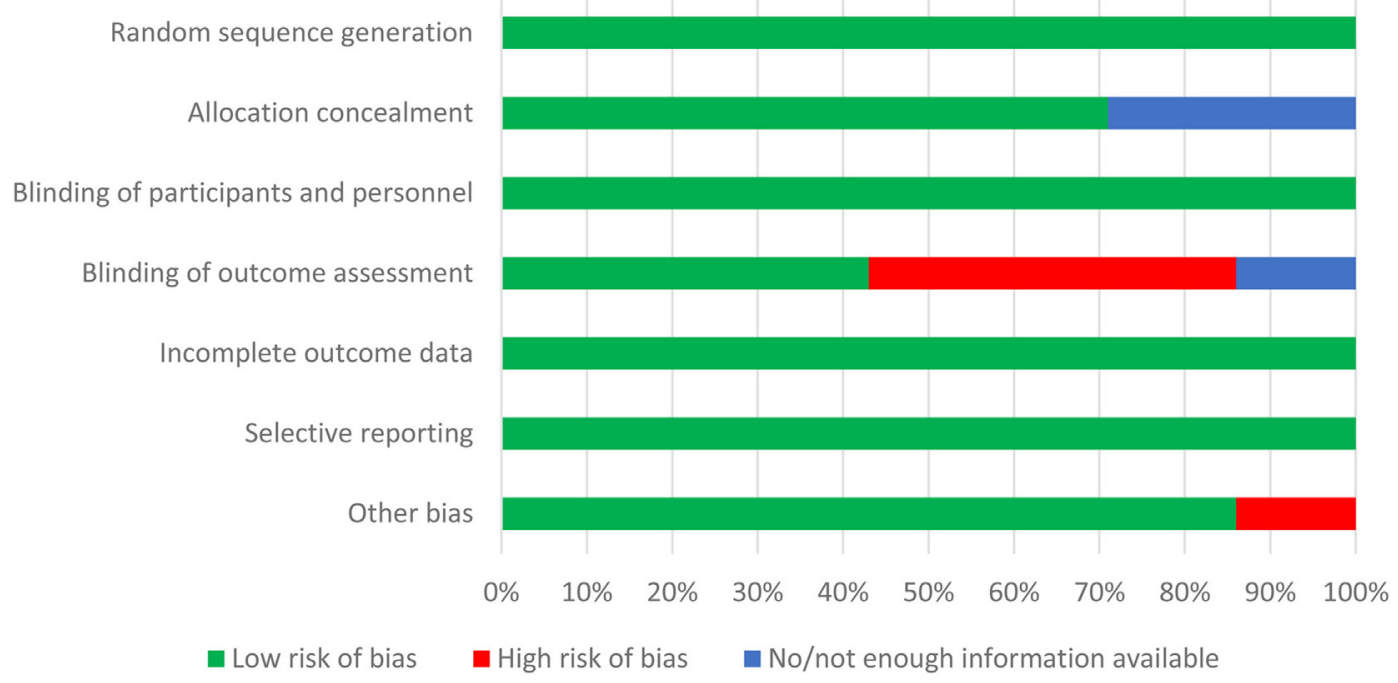

FIGURE 1 | Methodological quality assessment of the included randomized controlled trials evaluating the effect of prophylactic cranial irradiation on brain metastases in non-small cell lung cancer.

TABLE 1 | Study characteristics of the included RCTs evaluating PCI.

\begin{tabular}{|c|c|c|c|c|c|c|c|c|}
\hline Study & $\begin{array}{c}\text { Year of } \\
\text { publication }\end{array}$ & Local treatment & Stage & Brain imaging & $\mathrm{PCl}$ dose & Primary endpoint & $N^{\mathrm{a}}$ & $\begin{array}{c}\text { Systematic } \\
\text { Follow-up } \\
\text { for BM }\end{array}$ \\
\hline VALG & 1981 & RT alone & $A \|^{b}$ & Radionuclide scan & 10 Gy × 2 Gy & $\mathrm{BM}$ rate & 281 & No \\
\hline MDACC & 1984 & $\begin{array}{l}\text { Chemo-RT } \\
\text { RT alone }\end{array}$ & $|-|||$ & $\begin{array}{l}\text { Radionuclide } \\
\text { scan/CT scan }\end{array}$ & 10 Gy × 3 Gy & $\begin{array}{l}\text { CNS metastases } \\
\text { rate }\end{array}$ & 97 & No \\
\hline $\begin{array}{l}\text { RTOG } \\
8403\end{array}$ & 1991 & $\begin{array}{l}\text { RT alone } \\
\text { Surgery and RT }\end{array}$ & $|-|||$ & CT scan & 10 Gy × 3 Gy & Time to BM & 187 & No \\
\hline SWOG & 1998 & $\begin{array}{l}\text { Chemo-RT } \\
\text { RT alone }\end{array}$ & III & Unclear & 15 Gy × 2-2.5 Gy & OS rate & 226 & Not reported \\
\hline $\begin{array}{l}\text { RTOG } \\
0214\end{array}$ & 2012 & Chemo-RT & III & MRI scan & 15 Gy $\times 2$ Gy & OS rate & 340 & Yes \\
\hline $\mathrm{Li}$ & 2015 & Surgery-chemo & IIIA & MRI scan & 10 Gy × 3 Gy & DFS & 156 & Yes \\
\hline NVALT-11 & 2018 & RT alone & III & CT scan/MRI scan & 18 Gy × 2 Gy/12 Gy × 2.5 Gy/10 Gy × 3 Gy & $\begin{array}{l}\text { Symptomatic BM } \\
\text { rate }\end{array}$ & 175 & Yes \\
\hline
\end{tabular}

aNumber of eligible patients.

${ }^{b}$ All inoperable patients; stage not clear.

PCl, prophylactic cranial irradiation; RT, radiotherapy; Chemo; chemotherapy; BM, brain metastases; CNS, central nervous system; OS, overall survival; DFS, disease-free survival; $R C T s$, randomized controlled trials. 
NSCLC patients only, two studies $(7,8)$ included stage I, II, and III patients, and in one study (6) staging was unclear. For treatment of the primary tumor, two trials $(6,14)$ treated their patients with radiotherapy alone, one trial (11) used chemo-radiotherapy, and the four remaining trials used either combinations of chemoradiotherapy and radiotherapy alone $(7,9,10)$, chemotherapy and surgery (13), or radiotherapy and surgery (8). Brain imaging was mainly done by a radionuclide scan in two studies $(6,7)$. One study (8) used CT scans, three more recent studies $(11,13$, 14) used MRI and in one study $(9,10)$ the technology of brain imaging was unclear. Dosing of cranial irradiation ranged from 20 to $37.5 \mathrm{~Gy}$ ( 10 fractions of 2 Gy to 15 fractions of $2.5 \mathrm{~Gy}$ ).

\section{Incidence of BM After PCI}

Taken all RCTs together, in total, 1,462 patients were analyzed, including 717 patients who received PCI and 745 patients who did not. The BM incidence in the PCI arm ranged from 0.9 to $12.3 \%$, and from 11.0 to $30.7 \%$ in the non-PCI arm (Table 2). The overall effect estimate of the impact of PCI on the occurrence of BM is presented in Figure 2. The risk of developing BM was significantly decreased in the PCI arm compared to no PCI ( $13 \%$ reduction, RR 0.33 ; 95\% CI 0.22-0.45). Heterogeneity across the studies was low $\left(I^{2}=0 \% ; p=0.468\right)$. Furthermore, Egger's test indicated that smaller studies showed larger effect sizes $(p=0.048)$, which is also reflected in the asymmetric funnel plot (Figure 3). Nevertheless, results of the sensitivity analysis excluding small studies $(7,9,10)$ (weight $<10 \%$ ) were similar (RR 0.38; 95\% CI 0.24-0.51).

\section{PCI-Related Toxicity, QoL, and OS}

Few trials reported on PCI-related toxicity and QoL with most details in the study of Gore et al. (11) (Table3). Acute toxicity mostly included

TABLE 2 | Data on BM events [(a)symptomatic BM occurrence] and incidence of the included RCTs evaluating PCI.

\begin{tabular}{|c|c|c|c|c|c|c|c|}
\hline \multirow[b]{2}{*}{ Study } & \multicolumn{2}{|c|}{$\mathrm{PCl}$} & \multirow[b]{2}{*}{ Incidence (\%) } & \multicolumn{2}{|c|}{ No PCl } & \multirow[b]{2}{*}{ Incidence (\%) } & \multirow[b]{2}{*}{ Weight (\%) } \\
\hline & Events & Total & & Events & Total & & \\
\hline VALG & 7 & 136 & 5.1 & 16 & 145 & 11.0 & 10.5 \\
\hline MDACC & 2 & 46 & 4.3 & 14 & 51 & 27.5 & 9.0 \\
\hline RTOG 8403 & 8 & 93 & 8.6 & 18 & 94 & 19.1 & 12.2 \\
\hline SWOG & 1 & 111 & 0.9 & 13 & 115 & 11.3 & 8.7 \\
\hline RTOG 0214 & 13 & 163 & 8.0 & 32 & 177 & 18.1 & 20.9 \\
\hline $\mathrm{Li}$ & 10 & 81 & 12.3 & 29 & 75 & 38.7 & 20.5 \\
\hline NVALT-11 & 7 & 87 & 8.0 & 27 & 88 & 30.7 & 18.3 \\
\hline Total & 48 & 717 & & 149 & 745 & & \\
\hline
\end{tabular}

PCl, prophylactic cranial irradiation; BM, brain metastasis; RCTS, randomized controlled trials.

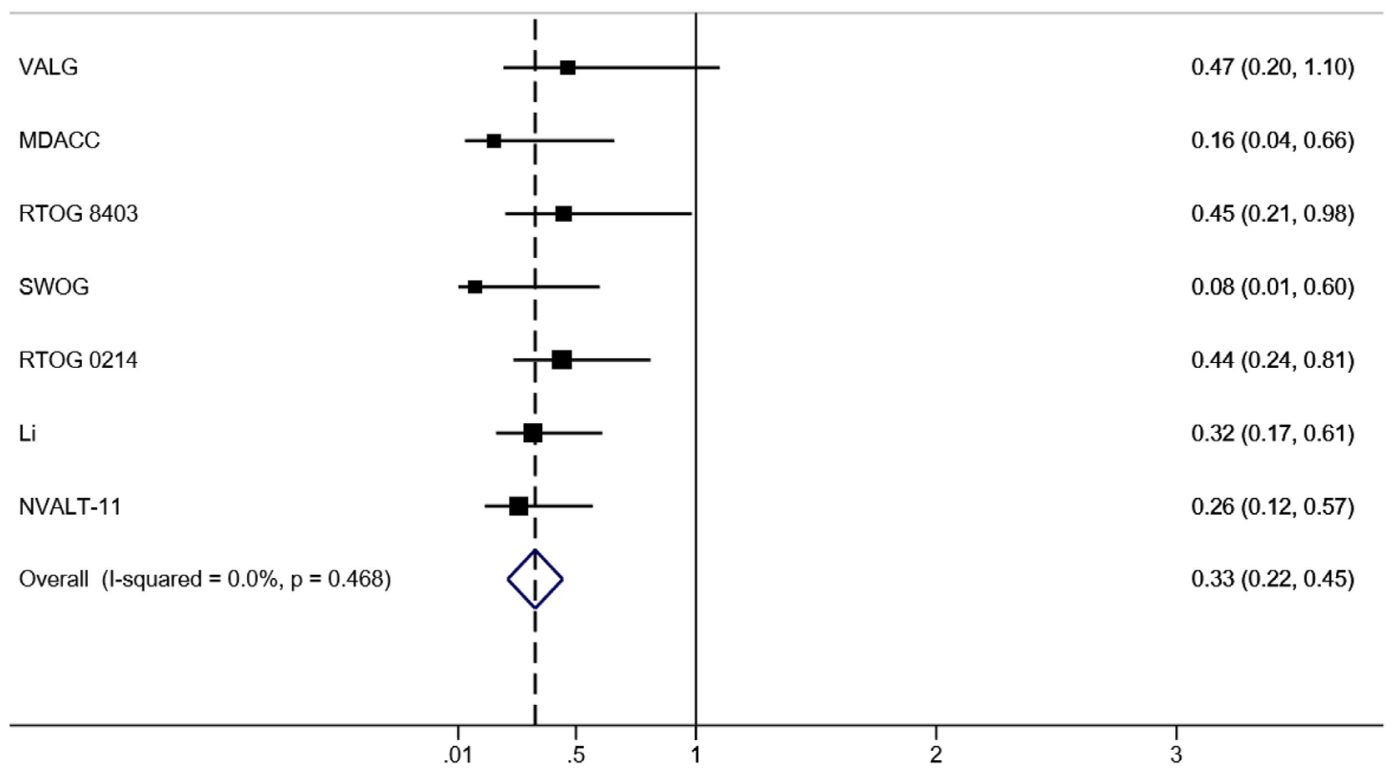

FIGURE 2 | Forrest plot of the meta-analysis of RCTs evaluating the effect of PCI on BM in NSCLC. Abbreviations: RR, relative risk; 95\% Cl, 95\% confidence interval; RCTs, randomized controlled trials; PCl, prophylactic cranial irradiation; BM, brain metastases; NSCLC, non-small cell lung cancer. 


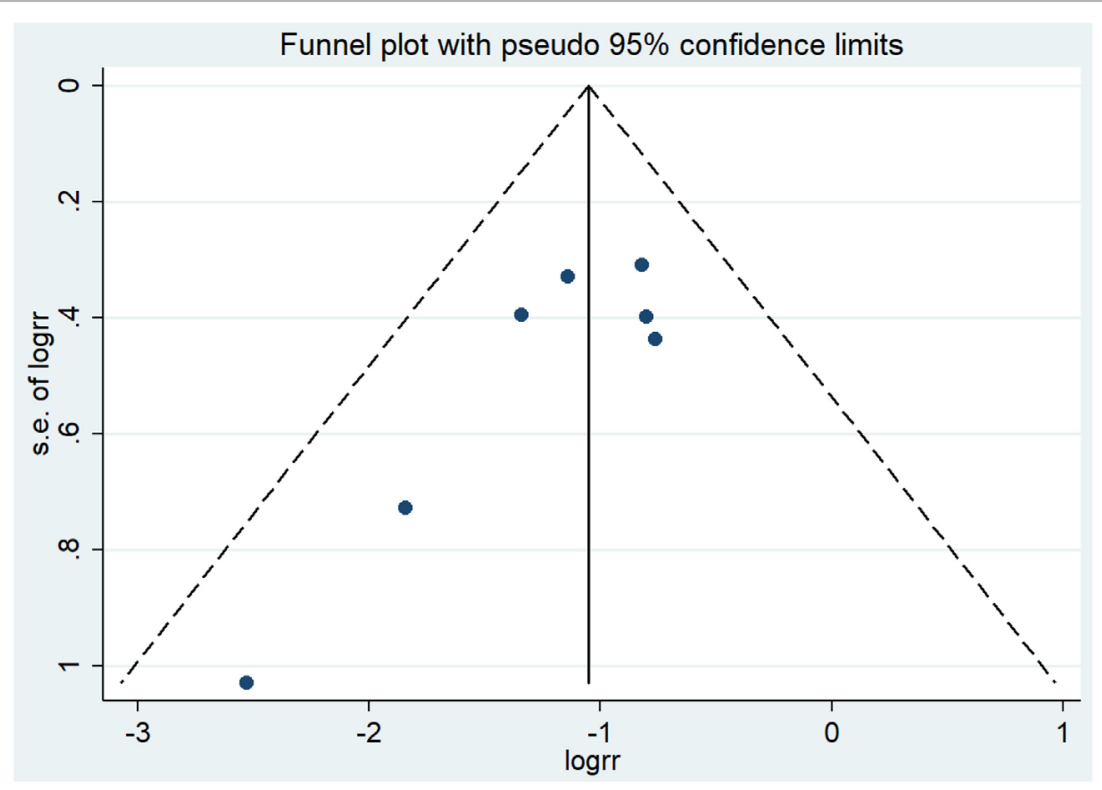

FIGURE 3 | Results of the funnel plot of RCTs evaluating the effect of PCI on BM in NSCLC. Abbreviations: logrr: logarithm of the relative risk; RCTs, randomized controlled trials; PCl, prophylactic cranial irradiation; BM, brain metastases; NSCLC, non-small cell lung cancer.

TABLE 3 | RCTs evaluating PCl-related toxicity and QoL in NSCLC.

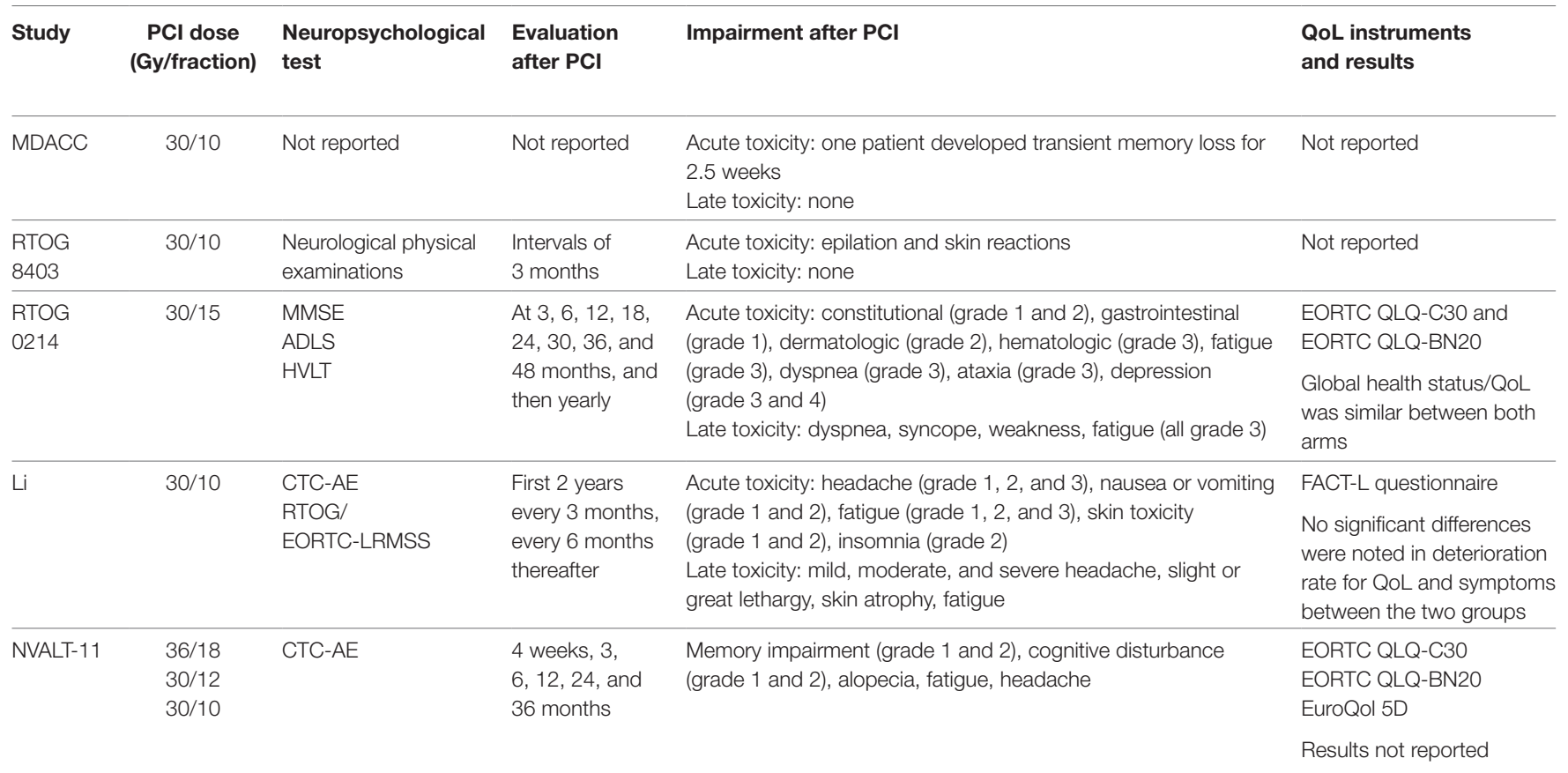

PCI, prophylactic cranial irradiation; QoL, quality of life; MMSE, Mini Mental Status Exam; ADLS, Activities of Daily Living Scale; HVLT, Hopkins Verbal Learning Test; CTCAE, Common Terminology Criteria Adverse Events; RTOG/EORTC-LRMSS, RTOG/ERTOC late radiation morbidity scoring schema; EORTC QLQ-C3O, EORTC quality of life questionnaire-C30; EORTC QLQ-BN2O, EORTC quality of life questionnaire-BN20; FACT-L questionnaire, Functional Assessment of Cancer Therapy-Lung questionnaire; NSCLC, non-small cell lung cancer; RCTs, randomized controlled trials.

fatigue, skin-related toxicity, and nausea or vomiting. Late toxicities such as headache, dyspnea, and lethargy were also reported in some of the included RCTs. Low grade (1 and 2) memory impairments and cognitive disturbances were only reported in the study of De Ruysscher et al. (14). Results reporting on QoL were limited, and no significant differences were observed between both arms. 
TABLE 4 | RCTs evaluating PCl-related OS in NSCLC

\begin{tabular}{llcc}
\hline Study & $\begin{array}{l}\text { Median follow-up } \\
\text { in months }\end{array}$ & $\begin{array}{c}\text { Median OS } \\
\text { in months } \\
\text { (PCl vs no PCl) }\end{array}$ & p-Value \\
\hline VALG & Not reported & Not reported & Not reported \\
MDACC & 13.6 (PCl), 12.7 (no PCl) & 60.3 vs 56.3 & Not significant \\
RTOG 8403 & Not reported & 8.4 vs 8.3 & 0.36 \\
SWOG & Not reported & 8.0 vs 11.0 & Significant \\
RTOG 0214 & 23.8 & 25.8 vs 24.8 & 0.86 \\
Li & $68.1(\mathrm{PCl}), 65.2$ (no PCl) & 31.2 vs 27.4 & 0.31 \\
NVALT-11 & 53.3 & 24.2 vs 21.9 & 0.56 \\
\hline
\end{tabular}

OS, overall survival; $P C l$, prophylactic cranial irradiation; NSCLC, non-small cell lung cancer; RCTs, randomized controlled trials.

In addition to BM occurrence, all included trials, except for the trial of Cox et al. (6), also reported on PCI-related OS in NSCLC (Table 4). Nearly all studies only report on short-term survival, and most trials did not use contemporary staging and systemic therapy. Taking these shortcomings in mind, no statistically significant OS difference was found between the PCI arm and no PCI arm, except for the study of Miller et al. $(9,10)$, which showed a significant OS benefit in favor of the no PCI arm $(p=0.004)$.

\section{DISCUSSION}

This study aimed to review published literature and revisit the role of PCI in the prevention of BM in NSCLC. The analysis included seven RCTs, involving 1,462 NSCLC patients in total. The current meta-analysis shows that the risk of developing BM was reduced in patients who received PCI compared to patients who did not (RR 0.33; 95\% CI 0.22-0.45).

Previously published results from reviews that investigated the role of PCI in the prevention of BM in NSCLC are in line with our findings. The most recently published meta-analyses of Sun et al. (4) and Xie et al. (19), evaluating the impact of PCI on BM occurrence in NSCLC, showed highly significant results in favor of PCI. However, these reviews could not evaluate the recent RCTs of Li et al. (13) and De Ruysscher et al. (14). Including the two most recent RCTs does not only add to the sample size of our meta-analysis, but the proper methodological quality and the use of more advanced brain imaging methods also add value to the conclusiveness of our results. Furthermore, unlike our study, the RCT of Pottgen et al. (12) was included in these meta-analyses. Local treatment was different between the two arms in this study (primary curative resection followed by postoperative thoracic radiation therapy vs chemotherapy and concurrent chemoradiotherapy followed by thoracic surgery). Therefore, we judged that it was not possible to assess the impact on prevention of BM attributable to PCI.

Although this is the largest, most recent review incorporating all available evidence from RCTs on the impact of PCI on the prevention of BM in NSCLC, there are also limitations. Egger's test and visual inspection of the funnel plot indicated the presence of publication bias. However, sensitivity analysis showed that excluding smaller studies from the meta-analysis did not much alter the results. Furthermore, assessment of the methodological quality of the included studies showed that for some items risk of bias was high. Nevertheless, most of these high bias risk items could be found in the studies $(7,9,10)$ that were excluded in the sensitivity analysis, and results remained largely similar to the original results.

The meta-analysis showed that the BM incidence was lower in patients who received PCI, but few trials also reported that PCI could cause toxicity resulting in a decline in QoL. Most occurring acute toxicities were fatigue, skin-related toxicity, and nausea or vomiting. Toxicities occurring on longer term were headache, dyspnea, and lethargy. In addition, the study of De Ruysscher et al. (14) also reported low-grade memory and cognitive functioning impairments. Therefore, the indications of PCI should be considered in the light of its potential (neuro)toxicity. QoL data were limited and not significantly different between the groups, no short-term OS benefit was shown, and the influence of PCI on long-term OS should be further investigated. It is necessary to further study the role of PCI in relation to neurocognitive decline and thus deterioration of QoL, and whether PCI could improve patients' long-term OS. In the era of more effective targeted therapy and immunotherapy, when extracranial disease is better controlled and patients are living longer, there may be increased importance of PCI. Moreover, hippocampal sparing techniques and medications such as memantine could be interesting future areas of research as alternatives to reduce toxicity and thus loss of QoL. Other areas of future research might include the role of MRI surveillance in combination with radical local treatment such as stereotactic radiosurgery or whole-brain radiotherapy. However, studies of the EORTC and RTOG showed that cure remains elusive in the overwhelming majority of these patients $(20,21)$.

\section{CONCLUSION}

The risk of developing BM was reduced in patients who received PCI compared to observation. To implement PCI as the standard treatment for patients with NSCLC, the impact of PCI on toxicity and QoL should be further investigated, as well as the impact on long-term OS. A future individual patient data meta-analysis with updated long-term OS could potentially produce definitive answers to these clinical questions.

\section{AUTHOR CONTRIBUTIONS}

WW wrote the initial draft of this review, with edits and revisions from all other authors, and especially BR and DR.

\section{SUPPLEMENTARY MATERIAL}

The Supplementary Material for this article can be found online at https://www.frontiersin.org/articles/10.3389/fonc.2018.00241/ full\#supplementary-material. 


\section{REFERENCES}

1. Vansteenkiste J, De Ruysscher D, Eberhardt WEE, Lim E, Senan S, Felip E, et al. Early and locally advanced non-small-cell lung cancer (NSCLC): ESMO clinical practice guidelines for diagnosis, treatment and follow-up. Ann Oncol (2013) 24(Suppl 6):vi89-98. doi:10.1093/annonc/mdt241

2. Peters S, Bexelius C, Munk V, Leighl N. The impact of brain metastasis on quality of life, resource utilization and survival in patients with non-smallcell lung cancer. Cancer Treat Rev (2016) 45:139-62. doi:10.1016/j.ctrv.2016. 03.009

3. Rangachari D, Yamaguchi N, VanderLaan PA, Folch E, Mahadevan A, Floyd SR, et al. Brain metastases in patients with EGFR-mutated or ALKrearranged non-small-cell lung cancers. Lung Cancer (2015) 88:108-11. doi:10.1016/j.lungcan.2015.01.020

4. Sun D-S, Hu L-K, Cai Y, Li X-M, Ye L, Hou H-Y, et al. A systematic review of risk factors for brain metastases and value of prophylactic cranial irradiation in non-small cell lung cancer. Asian Pac J Cancer Prev (2014) 15:1233-9. doi:10.7314/APJCP.2014.15.3.1233

5. Auperin A, Arriagada R, Pignon JP, Le Pechoux C, Gregor A, Stephens RJ, et al. Prophylactic cranial irradiation for patients with small-cell lung cancer in complete remission. Prophylactic Cranial Irradiation Overview Collaborative Group. N Engl J Med (1999) 341:476-84. doi:10.1056/ NEJM199908123410703

6. Cox JD, Stanley K, Petrovich Z, Paig C, Yesner R. Cranial irradiation in cancer of the lung of all cell types. JAMA (1981) 245:469-72. doi:10.1001/jama.1981. 03310300023013

7. Umsawasdi T, Valdivieso M, Chen TT, Barkley HTJ, Booser DJ, Chiuten DF, et al. Role of elective brain irradiation during combined chemoradiotherapy for limited disease non-small cell lung cancer. J Neurooncol (1984) 2:253-9. doi:10.1007/BF00253278

8. Russell AH, Pajak TE, Selim HM, Paradelo JC, Murray K, Bansal P, et al. Prophylactic cranial irradiation for lung cancer patients at high risk for development of cerebral metastasis: results of a prospective randomized trial conducted by the Radiation Therapy Oncology Group. Int J Radiat Oncol Biol Phys (1991) 21:637-43. doi:10.1016/0360-3016(91)90681-S

9. Mira JG, Miller TP, Crowley JJ. Chest irradiation vs. chest irradiation plus chemotherapy with or without prophylactic brain radiotherapy in localized nonsmall lung cancer: a Southwest Oncology Group Study. Int J Radiat Oncol Biol Phys (1990) 19:145. doi:10.1016/0360-3016(90)90693-E

10. Miller TP, Crowley JJ, Mira J, Schwartz JG, Hutchins L, Baker L. A randomized trial of chemotherapy and radiotherapy for stage III non-small cell lung cancer. Cancer Ther (1998) 1:229-36.

11. Gore EM, Bae K, Wong SJ, Sun A, Bonner JA, Schild SE, et al. Phase III comparison of prophylactic cranial irradiation versus observation in patients with locally advanced non-small-cell lung cancer: primary analysis of Radiation Therapy Oncology Group study RTOG 0214. J Clin Oncol (2011) 29:272-8. doi:10.1200/JCO.2010.29.1609

12. Pottgen C, Eberhardt W, Grannass A, Korfee S, Stuben G, Teschler H, et al. Prophylactic cranial irradiation in operable stage IIIA non small-cell lung cancer treated with neoadjuvant chemoradiotherapy: results from a German multicenter randomized trial. JClin Oncol (2007) 25:4987-92. doi:10.1200/ JCO.2007.12.5468

13. Li N, Zeng Z-F, Wang S-Y, Ou W, Ye X, Li J, et al. Randomized phase III trial of prophylactic cranial irradiation versus observation in patients with fully resected stage IIIA-N2 nonsmall-cell lung cancer and high risk of cerebral metastases after adjuvant chemotherapy. Ann Oncol (2015) 26:504-9. doi:10.1093/annonc/mdu567

14. De Ruysscher D, Dingemans A-MC, Praag J, Belderbos J, Tissing-Tan C, Herder J, et al. Prophylactic cranial irradiation versus observation in radically treated stage III non-small-cell lung cancer: a randomized phase III NVALT11/DLCRG-02 study. J Clin Oncol (2018) JCO2017775817. doi:10.1200/ JCO.2017.77.5817

15. Higgins JPT, Green S. Cochrane Handbook for Systematic Reviews of Interventions Version 5.1.0. The Cochrane Collaboration; (2011) [updated March 2011]. Available from: www.handbook.cochrane.org (Accessed: January 30, 2018).

16. StataCorp. Stata Statistical Software: Release 14. College Station, TX: StataCorp LP (2015).

17. Sterne JA, Egger M. Funnel plots for detecting bias in meta-analysis: guidelines on choice of axis. JClin Epidemiol (2001) 54:1046-55. doi:10.1016/ S0895-4356(01)00377-8

18. Egger M, Smith GD, Schneider M, Minder C. Bias in meta-analysis detected by a simple, graphical test. BMJ (1997) 315:629-34. doi:10.1136/bmj.315. 7109.629

19. Xie S, Li M, Zhou C, Song X, Wang C. Prophylactic cranial irradiation may impose a detrimental effect on overall survival of patients with nonsmall cell lung cancer: a systematic review and meta-analysis. PLoS One (2014) 9:e103431. doi:10.1371/journal.pone.0103431

20. Kocher M, Soffietti R, Abacioglu U, Villà S, Fauchon F, Baumert BG, et al. Adjuvant whole-brain radiotherapy versus observation after radiosurgery or surgical resection of one to three cerebral metastases: results of the EORTC 22952-26001 study. JClin Oncol (2011) 29:134-41. doi:10.1200/ JCO.2010.30.1655

21. Sperduto PW, Wang M, Robins HI, Schell MC, Werner-Wasik M, Komaki R, et al. A phase 3 trial of whole brain radiation therapy and stereotactic radiosurgery alone versus WBRT and SRS with temozolomide or erlotinib for non-small cell lung cancer and 1 to 3 brain metastases: Radiation Therapy Oncology Group 0320. Int J Radiat Oncol Biol Phys (2013) 85:1312-8. doi:10.1016/j.ijrobp.2012.11.042

Conflict of Interest Statement: LH: Consulting or Advisory Role: Boehringer Ingelheim and BMS. Fees for lectures: MSD, Astra Zeneca, Roche. Research grant: Roche. A-MD: Consulting or Advisory Role: Genentech (Inst), MSD Oncology (Inst), AstraZeneca (Inst), Pfizer, Eli Lilly (Inst), Boehringer Ingelheim (Inst), Bristol-Myers Squibb, Clovis Oncology (Inst). DR: Consulting or Advisory Role: Bristol-Myers Squibb (Inst), Genentech (Inst), Merck Serono (Inst), AstraZeneca (Inst), Celgene (Inst). Research Funding: Bristol-Myers Squibb (Inst).

The remaining authors declare that the research was conducted in the absence of any commercial or financial relationships that could be construed as a potential conflict of interest.

Copyright (c) 2018 Witlox, Ramaekers, Zindler, Eekers, van Loon, Hendriks, Dingemans and De Ruysscher. This is an open-access article distributed under the terms of the Creative Commons Attribution License (CC BY). The use, distribution or reproduction in other forums is permitted, provided the original author $(s)$ and the copyright owner are credited and that the original publication in this journal is cited, in accordance with accepted academic practice. No use, distribution or reproduction is permitted which does not comply with these terms. 